\title{
Lyrics and language awareness
}

\author{
Valentin Werner \\ University of Bamberg \\ valentin.werner@uni-bamberg.de
}

\begin{abstract}
Commercially successful pop lyrics are an important part of students' lives, represent authentic language material, are easily accessible, and may thus constitute a helpful starting point for various aspects of foreign language education. Despite this, they seem to be underexploited, especially when topics such as grammar instruction are tackled. This may be due to their (traditionally ascribed) "low culture" status and the undesired presence of allegedly ungrammatical content, notably in terms of non-standard features. Based on a corpus of c. 550,000 words, this paper will present an analysis of the salience of such features in English pop lyrics. The results suggest that the material studied actually features a rich array of nonstandard grammatical phenomena, such as multiple negation, ain't as auxiliary, $m e$ instead of $I$, copula deletion, etc. (as commonly proscribed in English language education). From a pedagogical perspective, it is therefore argued that using lyrics in the classroom may offer students a welcome opportunity to engage with various types of grammaticality, introducing them to authentic language in a naturalistic way. More specific issues to be addressed with the eventual aim of raising students' language awareness through working with pop lyrics are that assessments of grammaticality are (i) very much context-dependent, for instance in terms of acceptability of certain structures and variants in different registers (e.g. lyrics vs. conversation vs. formal writing) and (ii) may also differ across varieties of English represented in the lyrics (e.g. various British dialects and sociolects, African American English as represented in rap, Jamaican Creole as represented in reggae, etc.).
\end{abstract}

\section{Keywords}

lyrics; pop culture; language awareness; grammar; non-standard; EFL 


\section{Introduction}

It is universally acknowledged that pop culture is a pervasive phenomenon with a strong "cultural reach and penetration" (Coupland, 2011: 576) and thus with a strong impact on everyday language (Bell \& Gibson, 2011; Werner, 2018). In addition, it has been stated that especially (English) pop music is ubiquitous in Western societies (Trotta, 2010, 2013) and its lyrics therefore arguably can be seen as the epitome of a pop cultural text.

From the perspective of foreign language education (FLE) - despite some persistent reluctance (see Section 2) - it has also been increasingly recognized that pop music and its lyrics are an important part of students' lives and may constitute a helpful starting point for various FLE aspects (Werner \& Tegge, forthcoming). ${ }^{1}$ Rationales mentioned for using pop music in FLE derive from various areas. From a linguistic point of view, it has been argued that "songs are form-meaning units to be included in any complete language description" (Turpin \& Stebbins, 2010: 1), even though in actual reality they represent an underresearched text type (Werner, 2018). Studies in cognitive psychology have suggested that the multi-channel processing (music + language) involved when dealing with pop songs in connection with their repetitiveness and schematicity increases processing depth and facilitates memory and verbal recall (see, e.g., Schön et al., 2005; Jantzen et al., 2016; Patel, 2017). Studies with a focus on the psychology of learning and motivation have found that using songs in FLE may lead to lowered levels of foreign language (FL) anxiety as well as to a positive affective emotional attachment of the learners, eventually resulting in higher intrinsic motivation, a crucial variable in any FL classroom (see, e.g., Syed, 2001; Sposet, 2008; Loewen, 2015; Dolean, 2016; Tomlinson, 2017). Finally, using pop music lyrics also seems to be embraced by FLE practitioners (Alisaari \& Heikkola, 2017; Tegge, 2018), especially due to aspects such as their wide availability and easy accessibility (e.g. on lyrics webpages or on video platforms; Marone, 2018) and as they represent authentic textual material (as often demanded by syllabi) that also connects to the lifeworld of their learners

\footnotetext{
${ }^{1}$ It is evident that English as a target language has the benefit of being "the" language of pop culture (Werner, 2018). Accordingly, the study will rely on English material to illustrate its points. However, many of the rationales presented are applicable in the broader domain of FLE and thus other target languages as well.
} 


\section{Nordic Journal of Modern Language Methodology}

2019, 7 (1), 4-28 Peer reviewed

(potentially serving as another motivational factor; cf. Dörnyei, 2001). ${ }^{2}$ Researchers have further acknowledged that working with pop music lyrics is suitable for all learner levels (see, e.g., Bértoli, 2018; Mobbs \& Cuyul, 2018).

In spite of these arguments, pop lyrics still seem to be underexploited in FLE classrooms (Engh, 2013; Scott Langeland, 2013), with grammar being the area addressed least often (Gosselin, 2017; Werner, forthcoming). This is also particularly reflected in current FLE materials and textbooks (Keskinen, 2014; Summer, 2018; Tegge, 2018), where song-based activities are present but often used as supplementary material only and are restricted to listening comprehension and general writing tasks (Summer, 2011). Topics such as the presentation of grammar are usually excluded (Lems, 2005; Ziegler, 2016). This may be due to the (traditionally ascribed) "low culture" status of pop culture and its artefacts, and - especially for lyrics - the undesired presence of "ungrammatical" content, notably in terms of non-standard features (on which see further Section 2).

In the following, I will suggest that the occurrence of non-standard features (as occurring in pop lyrics as authentic texts) ${ }^{3}$ and their alleged ungrammaticality should be embraced rather than ignored in FLE. While students certainly should be familiarized with the conventions of standard English, dealing with such features (and contrasting them with standard usage) opens avenues for work on the broader goal of raising the students' (meta-)language awareness. Language awareness, defined as "explicit knowledge about language, and conscious perception and sensitivity in language learning, language teaching and language use" (ALA; cited in Svalberg, 2012: 376), includes issues such as register awareness (context-dependence of the acceptability of various structures) as well as the recognition of variation and complexity (for pluricentric languages with various dialects and sociolects), ${ }^{4}$ and has been shown to be an

\footnotetext{
${ }^{2}$ Surveys have found students to consume between two and four hours of pop music daily (North et al., 2000; Dethier, 2003; Summer, 2011), with listening times probably having increased even further in recent years due to the widespread availability of technology (Nielsen, 2017). It is evident that this is much more than actual contact time in the foreign language classroom, so that additional opportunities for incidental and informal learning - an aspect not treated in this paper - arise (see also Preisler, 1999; Duff \& Zappa-Hollman, 2013; Pavia et al., 2019).

${ }^{3}$ For a more detailed discussion of the affordances of using authentic texts and how using pop lyrics can contribute toward authentication on part of the learners, see Werner (forthcoming).

${ }^{4}$ See also Thaler (2012), who identifies the realization that there are different Englishes as one of the potential wider aims of using pop lyrics in grammar instruction (see also Section 4.2).
} 
important generic factor for successful FL learning (Andrews, 2008). I will connect this argument to pop lyrics and will suggest that using this type of authentic material is particularly suitable for such purposes, as it features both standard and non-standard usage and represents a "special register" (Werner, 2012: 43) from a linguistic point of view.

To contextualize the present research, Section 2 will provide a brief historical sketch of positions towards using pop lyrics in FLE. ${ }^{5}$ Section 3 presents the empirical portion of this study and, after introducing the data and methodology used, reports the results of a corpus-based exploration of pop lyrics with a focus on the presence and scope of non-standard usages. In light of the findings of the corpus analysis, Section 4 addresses the issues of grammaticality and acceptability, and relates this to the broader domain of language awareness. Section 5 provides an overall summary.

\section{A brief history of lyrics in FLE}

This section partly draws on and presents an update of the historical overview of (pop) lyrics use in FLE provided in Murphey (1990). It starts with the observation that even though there were a few early advocates of using musical material (Stocker, 1923), the general position taken in the middle of the $20^{\text {th }}$ century was informed by cultural pessimism. In mainstream FLE circles, pop songs were viewed as "sheer rubbish" with "dubious musical value", and, as regards language, characterized by "ungrammatical forms" and "ugly slang" (quotes from Gravenall, 1949: 126), by and large leading to their avoidance. A more positive view emerged with the introduction of textbooks that adapted activities derived from the audio-lingual method, where exercises with lyrics were deemed more enjoyable than drills (Billows, 1961). However, a fear of "irregular structure" and "incorrect [...] patterns" (quotes from Richards, 1969: 163) in folk and pop songs persisted, and pedagogical songs (i.e. with lyrics adapted to standard usage) were recommended instead.

\footnotetext{
${ }^{5}$ Related issues not considered in the present analysis are folk and children's songs, pedagogical songs as represented in Hancock's (2006) Singing Grammar (see also R. Werner, 2018) as well the broader effects of vocal pop as background music (e.g. while learning vocabulary; de Groot \& Smedinga, 2014) or of musical ability on linguistic ability (Gottfried, 2007).
} 
The 1970s and 1980s then recognized lyrics as an "overlooked resource" (Dubin, 1975: 1), and argued that lyrics are suitable for the teaching of pronunciation and cultural aspects. In addition, language educators acknowledged the motivational potential of pop lyrics, but simultaneously pointed to the issue of a comparatively unspecific and optional use where "songs are often used as a carrot - a reward for tired teachers and students on a Friday of a long week" (Williamson \& Reeve, 1987: 33). As already indicated above (see Section 1), this underexploitation as mere "time fillers" (Abbott, 2002: 11) or a "kind of relief from pursuing what is perceived as the real purpose of English classes - studying for exams" (Smith, 2003: 115) appears to have persisted.

Recent analyses have suggested that pop lyrics - if they are present in materials at all are used as supplementary material without any concrete language-related added value and are poorly used especially in the area of grammar teaching and in materials for higher proficiency levels (Huber, 2010; Summer, 2011; Tegge, 2015, 2018). Even if using songs and lyrics in FLE is advocated, grammar-related tasks are reduced to simple "error correction" exercises with nonstandard items being merely seen as "mistakes" (see Budden, 2008 for a pertinent example). Such an approach can be considered deficient due to an overemphasis on standard usage and the inherent ignorance of issues relating to language variation and diversity (see further Section 4).

On a different note, FLE scholars have deplored that pop lyrics (and other pop culture material) are not only side-lined in practice but also underresearched. This results in a lack of "both theoretical underpinnings and principled rationales" (Zhou, 2016: 164) for their use, notwithstanding some work in related areas such as psychology (see Section 1 and, e.g., FonsecaMora \& Gant, 2016) and efforts with a strong practical focus in the form of intervention studies (testing the efficiency of lyrics-based teaching; e.g. Li \& Brand, 2009; see also the review Werner, submitted a) and developments of concrete lesson plans and activities (e.g. Lorenzutti, 2014; contributions in Arnold \& Herrick, 2017 or Thaler, 2018).

\section{The grammar of pop lyrics}

The general question addressed in this section is: How (non-)standard are pop lyrics after all? This serves to provide an empirical basis for claims that the language of pop lyrics is 
"ungrammatical" (in the sense described above, i.e. containing many non-standard elements). ${ }^{6}$ It will further be particularly interesting to see which kinds of non-standard elements occur. Note that lexical aspects (e.g. lexical innovations and slang) would merit a separate treatment and thus are disregarded here apart from where they impact on the lexicogrammar.

\subsection{Data and Method}

Findings are based on LYPOP, a self-compiled corpus of contemporary English pop lyrics. Evidently, there are variuos ways of deciding what counts as "pop(ular)" in the first place. The main criterion for inclusion of material for LYPOP was commercial success of the songs as this was deemed a reasonably unbiased approach that results in a representative selection. To this end, all the lyrics were included from the top ten albums of the year-end charts of the years 20012016 as determined by the Official Charts Company (www.officialcharts.com), a British music industry-related organization that provides chart synopses based on the collection and analysis of record sales data.

A few steps were necessary to ensure validity, internal consistency and searchability of the data. First, all non-English songs were excluded. ${ }^{7}$ Lyrics (in the form of HTML files) were retrieved semi-automatically from the lyrics page AZlyrics.com with the DownThemAll! browser plugin for Firefox. While a considerable number of lyrics pages exists, ${ }^{8}$ AZlyrics.com was chosen as a source as it offers users the option to correct lyrics once they have been submitted, leading to

\footnotetext{
${ }^{6}$ It is evident that this question could also be approached in a purely quantitative fashion (e.g. How many standard second person singular pronouns do we find and how many non-standard ones? What is their relative proportion?). Arguably, the establishment of such information may be of more interest to descriptive linguists rather than to language educators and learners or materials designers. Please refer to the findings of an earlier corpus-based study of pop lyrics, which generally has found that "in the large majority of cases, regular [i.e. standard] morphological and syntactic patterns are employed" (Werner, 2012: 33-34).

${ }^{7}$ A reviewer wondered about the proportion of non-native performers and writers of English lyrics. It can confidently be stated that their share is marginal, thus not influencing the overall results (e.g. in terms of introducing a substantial amount of (non-standard) interlanguage features into the data).

${ }^{8}$ The large number of lyrics webpages available and their high user traffic numbers (see, e.g., www.alexa.com/topsites/category/Arts/Music/Lyrics) seem to counter arguments that listeners only focus on the music and disregard lyrics altogether. Note that major search engines such as Google or Bing have started to display lyrics (and videos) directly on the search results page after a query for a particular song has been entered, and that music streaming services such as Spotify (which increasingly account for music revenues worldwide; www.statista.com/statistics/456524/digital-music-revenue-in-worldwide-2023-forecast/) also offer one-click options for displaying lyrics while a song is played (Gabe, 2015). These developments may have led to the recent reduction of overall traffic on specialized lyrics websites (see, e.g., www.trafficestimate.com/azlyrics.com).
} 
some kind of inherent quality control, and as it has proved to provide accurate transcriptions in other linguistic studies of lyrics (see, e.g., Hagedorn, 2019; Motschenbacher, 2016; Werner, submitted b). Yet, unwanted metainformation (such as indications of verses, instrumental solos, etc.) had to be removed with the help of a Notepad $++\operatorname{script}^{9}$ using regular expressions before the files could be converted to plain text format (TXT) readable by the corpus software.

Eventually, the material comprised 1,842 songs by 91 different artists/bands and had a size of 547,758 words (12,894 word types). While the transcriptions were largely accurate (see above), another post-processing step was applied to the data. It aimed at resolving minor inaccuracies as regards spelling variants (e.g. 'cause vs. cause vs. cuz vs. coz ('because')), which were normalized (to 'cause in this case). This procedure was supported by the VARD 2 tool (Baron, 2017). Corpus concordance searches were conducted using AntConc (version 3.5.6; Anthony, 2018), an established freeware corpus tool.

\subsection{Non-standard features in pop lyrics}

The selection of grammatical items presented in the following is loosely based on the extensive list of non-standard features established in the electronic World Atlas of Varieties of English (eWAVE; Kortmann \& Lunkenheimer, 2013), a survey-based, typologically-inspired "interactive database on morphosyntactic variation in spontaneous spoken English mapping 235 features from a dozen domains of grammar" (see www.ewave-atlas.org). ${ }^{10}$ eWAVE was chosen as a baseline for establishing "non-standardness" as it is widely used among linguists and freely available online, therefore also potentially serving as a point of reference for language educators.

It is evident, though, that there are different approaches to what "non-standard" comprises and that boundaries may be fuzzy. Some of the items listed in the following could equally be termed mere regional variants or could be viewed as being part of an "informal (spoken) standard" (Joe Trotta, p.c.) that takes account of innovative variants. Conventionally, however, regional variants (as well as usages in language contact settings and highly informal variants) are

\footnotetext{
9 Thanks are due to Fabian Vetter for support.

${ }^{10}$ The coverage of eWAVE is fairly comprehensive. It contains information on "50 varieties of English (traditional dialects, high-contact mother-tongue Englishes, and indigenized second-language Englishes) and 26 English-based Pidgins and Creoles in eight Anglophone world regions" (www.ewave-atlas.org).
} 
considered to represent non-standard usage (see, e.g., www.ewave-atlas.org/introduction), and "would be regarded by linguistic purists as ungrammatical” (Cullen \& Kuo, 2007: 365). Thus, a broad conceptualization of "non-standard" is applied here. In any case, it is unlikely that pertinent features are a regular part of FLE textbooks, which traditionally are oriented toward (written) standard usage, and where (spoken/conversational) informal usage can be considered an emerging focus only (Carter \& McCarthy, 2017; Fernández Gavela, 2015; Werner, forthcoming).

Rather than providing a comprehensive list of (the potential 235) non-standard features (available at www.ewave-atlas.org/parameters) in pop lyrics, which would go well beyond the scope of this paper, the aim is to illustrate the breadth of linguistic variation that can be found in this text type, as this will serve as a basis for dealing with the issues of grammaticality and language awareness (Section 4). Thus, salient examples from each of the 12 broader grammatical domains listed in eWAVE are selectively chosen based on frequency criteria. ${ }^{11}$

\section{Pronouns}

A lexicogrammatical area where considerable variation occurs in the LYPOP corpus is alternative forms or phrases for the second person pronoun you (eWAVE features 34/35). The corpus search retrieved the forms $y a$ (as in ((1)) and its spelling variant $y u h,{ }^{12}$ youse and its spelling variant youz (as in (2)) as well as the plural forms y'all (as in (3)), you guys (as in (4)), and you people (as in (5)).

(1) He doesn't love ya, I can tell by his charm (Justin Timberlake: Señorita)

(2) Whatever youz was working I hope that it was worth it baby (Usher: Truth hurts)

(3) Y'all stuck on super A-shit (Black Eyed Peas: Boom boom pow)

(4) Oh my god you guys, I totally had more than 300 calories today (P!nk: Stupid girls)

(5) 'cause all you people are vampires (Arctic Monkeys: Perhaps vampires is a bit strong but)

\footnotetext{
${ }^{11}$ See also Trotta (2013) for a qualitative analysis of older material based on the Am I Right page (www.amiright.com) that deals with Mondegreens in lyrics.

${ }^{12}$ A reviewer rightly pointed out that $y a$ and $y u h$ could be considered as mere spelling variants of you. This applies to unstressed contexts only, of course.
} 


\section{Noun phrase}

The corpus data also serve to illustrate variation in the noun phrase, for instance as regards the use of them instead of demonstrative those (eWAVE feature 68), as illustrated in (6) and (7).

(6) In one of them long black limousines (Rod Steward: Legless)

(7) We ain't like them other fools, who don't compare to us (Jay Z: Come and get me)

Note that we also find internal variation between the standard variant those and the non-standard variant, as in (8).

(8) Roll those eyes girl, twist them hips girl (Destiny's Child: Fancy)

Another highly salient feature (at least from the viewpoint of standard grammar) within the noun phrase is the extension of synthetic marking, which results in a regularized comparison/ superlative pattern (eWAVE feature 79), illustrated in (9) to (11). Example (11) even represents a double comparative (cf. eWAVE feature 78), combining suppletion and synthetic marking.

(9) But the beautifullest treasures lie in the deepest blue (Coldplay: Army of one)

(10) Spotlight, bad baby, you've got a flair for the violentest kind of love anywhere out there (Lana del Rey: Belair)

(11) Diamonds are my bestest friend. (Lana del Rey: Body electric)

\section{Adverbs (and prepositions)}

Further exemplifying variation within the domain of function words, the data yield non-standard usages within the "minor" categories of adverbs (as well as prepositions - not illustrated here). For instance, we find degree modifier adverbs that are unmarked; that is, they formally correspond to adjectives (eWAVE feature 220). This is illustrated in (12) to (14) and could be 
considered as qualifying as one of the informal spoken standard usages (of American English) mentioned above.

(12) I know we're gonna have a real good time, yeah (Steps: Stomp)

(13) I've been an awful good guy (Michael Bublé: Santa baby)

(14) Damn near cried when I got that phone call (Usher: Confessions part II)

\section{Adverbial subordination}

A corpus finding again related to the area of adverbs is the occurrence of double conjunctions that link two clauses (eWAVE feature 214), as shown in (15), where a single conjunction would appear in standard usage.

(15) I was giving good loving yet still you strayed (Gabrielle: If you really cared)

\section{Verb morphology}

Turning to the domain of verbal morphology, the LYPOP data yield highly salient instances such as the usage of was for were in conditional clauses (eWAVE feature 147), as in example (16).

(16) If I was you, I wouldn't like me either (Drake: Views)

A different lexicogrammatical aspect is the leveling of past tense/past participle forms. Corpus searches retrieve examples of both past participles replacing past tense forms (eWAVE feature 131), as in (17) and (18), ${ }^{13}$ and past tense forms replacing the past participle (eWAVE feature 130), as in (19).

(17) Oh, I never done this before (Bruno Mars: Natalie)

(18) You ask me where I been? (Lana del Rey: Burning desire)

\footnotetext{
${ }^{13}$ Examples (17) and (18) could also be interpreted as elliptical forms (cf. Green, 2007).
} 


\section{Nordic Journal of Modern Language Methodology}

2019, 7 (1), 4-28 Peer reviewed

(19) If your girlfriend has went to any season opener basketball game [...] (Drake: Child's play)

\section{Tense and aspect}

Closely related to the foregoing are ways of how tense and aspect is expressed. One case in point is the use of done (+ past participle) as a marker to express completed action/perfectivity (eWAVE feature 104), illustrated in (20).

(20) I done seen you before what you got on them big rims (Lady Gaga: Starstruck)

\section{Modal verbs}

Even though pop lyrics have been shown to reproduce rather than to introduce innovative variants (Werner, 2012), recently emerging grammatical items such as quasi-modals expressing aspectual meanings (eWAVE feature 126), as in (21) and (22), occur in the LYPOP data. Some of these may have a strong regional association, such as fixin $(g)$ to with the US South (see Staub \& Zenz, 2017).

(21) Shit's finna [future marker] get thick again (Eminem: No love)

(22) Excuse me but who are you fixing to [getting ready/preparing to] be? (Rihanna feat. Nicki Minaj: Raining men)

\section{Negation}

When we turn from lexicogrammar to aspects related to morphosyntax, a highly salient feature occurring in the data is multiple negation, alternatively referred to as negative concord (eWAVE feature 154). Multiple negation involves the negative marker not/n't in combination with another negative or negated item, ${ }^{14}$ variously exemplified in (23) to (25). Note that a standard pattern of negation (didn't feel a thing instead of potentially didn't feel no thing) appears in (24).

\footnotetext{
${ }^{14}$ Note, crucially, that multiple negative forms (unlike mathematical operators) do not cancel each other out. As the label implies, also more than two negative items may occur, for instance as in I ain't never did no wrong (Elvis Presley: One night).
} 
(23) We don't need nobody 'cause we got each other (Lana del Rey: Body electric)

(24) And I didn't feel a thing, so baby don't feel no pain (Eminem: When I'm gone)

(25) Fed up of biding your time when I don't get nothing back (Adele: Tired)

Multiple negation often occurs in combination with the non-standard negator ain't, which may either be used as a negated form of be (eWAVE feature 155), as in (26) and (27), or have (got to) (eWAVE feature 156), as in (28), there involving additional contraction.

(26) On the avenue, there ain't never a curfew (Alicia Keys: Empire state of mind part II)

(27) Ain't no chance of the record company dropping me (Robbie Williams: Kids)

(28) You ain't gotta answer none of my calls (Justin Bieber: No pressure)

Note further that ain't (not necessarily involving multiple negation) may be used as a generic negator appearing before a main verb (eWAVE feature 157), comparable to the above examples replacing either a negated form of have, as in (29), of be, as in (30), or of do, as in (31) and (32). The main verb following the negator may either be inflected (examples (29) and (30)) or appear in its base form (examples (31) and (32)).

(29) I've tried in this department but I ain't had no luck with this (Eminem: Yarn)

(30) I ain't meant to be here I'm meant to be free (Plan B: Free)

(31) But I was tired of playin' the role like I ain't know that she get around (Timbaland: Time)

(32) See I ain't try to hurt you baby (Bruno Mars: Runaway baby)

\section{Agreement}

A widespread non-standard feature as regards agreement is the use of existential there's (and related forms such as there is and there was) with plural subjects (eWAVE feature 172). This is exemplified in (33) to (36). 
(33) There's four and twenty million doors on life's endless corridor (Oasis: The masterplan)

(34) I temporarily forgot there's better days to come (Dido: See you when you're 40)

(35) There's lovers in the backseat (Scissor Sisters: Lovers in the backseat)

(36) There was tears on the steering wheel, dripping on the seat (Arctic Monkeys: Do me a favor)

In addition, the LYPOP data yield other agreement-related features, such as the deletion of auxiliary be in contexts where the progressive would occur in the standard (eWAVE feature 174), as shown in (37) and (38). Note that example (38) also contains deletion of be as a copula (you Ø cute; eWAVE feature 177).

(37) Hey, hey, hey, hey, hey what $\varnothing$ you looking at (Take That: Kidz)

(38) You $\varnothing$ breaking my focus boy you $\varnothing$ cute and you $\varnothing$ balling (Beyoncé: Video phone)

\section{Complementation, relativization and discourse organization}

The LYPOP data further serve as a source for features related to the clause and discourse level such as as/than what in comparative clauses (eWAVE feature 204), as in (39), that or what as a relative pronoun in non-restrictive relative clauses (eWAVE feature 185), as in (40), and the use of quotative like (eWAVE feature 235), as in (41).

(39) Tryna live on more than what I got (Bruno Mars: Liquor store blues)

(40) It's the oldest chair that's so comfortable (Gary Barlow: More than life)

(41) I'm like "My skin, is it startin' to work to my benefit now?" (Eminem: White America)

\section{Discussion: Beyond structure}

As could be seen from the foregoing (Section 3.2), a wide range of non-standard items (as defined by the eWAVE feature list) occurs in pop music lyrics, an authentic and widespread text type. This does not necessarily imply that these items, as well as other informalisms, are highly frequent (Werner, 2012). Indeed, standard variants of the features described above can also easily 
be found in the data and usually outnumber the non-standard variants by far (and rare features of standard grammar may be introduced equally well through lyrics). ${ }^{15}$ However, the items listed are highly salient due to their association with non-standardness and/or informality (see also Trotta, 2013), areas commonly ignored or at least underrepresented in FLE (see Section 3.2). They are also salient as they feature in a register not commonly treated in FLE materials, but featuring centrally in the lives of many, if not all, FL students.

The question arises how this salience should be exploited in the language classroom beyond a mere introduction or discussion of individual structural features or combinations thereof (as advocated in Saricoban \& Metin, 2000, for instance). In the following, it is suggested that the occurrence of such material is a welcome opportunity to consider issues of grammaticality and acceptability with the eventual aim of raising FL students' overall language awareness.

\subsection{Grammaticality and register awareness}

A first issue worth discussing is that assessments of grammaticality are very much contextdependent (Fetzer, 2004), for instance in terms of acceptability of certain structures and variants in different registers. Non-standard features as used in pop lyrics could be contrasted to usages in conversation and formal writing (as two potential points of comparison) to bring to the students' attention that - rather than representing unified and uniform wholes - languages have diversified registers. Above all, raising register awareness can be considered a goal in itself, as it relates to relevant aspects such as stylistic and pragmatic appropriateness (why is the negator ain't appropriate in lyrics and informal conversation, but not in a job interview or a written application?) and resulting social consequences. A related issue is an explicit consideration of the fuzziness between and changing nature of the categories "(non-)standard" and "(in)formality" (is the use of if I was instead of if I were in the subjunctive a non-standard or rather merely an informal feature?; see Section 3.1). Further, assessments of grammaticality and acceptability could be related to broader sociolinguistic topics such as symbolic capital, language and identity, style shifting and matters of covert and overt prestige (on which see further Section 4.2; cf. Trotta, 2013). Simultaneously, this addresses the fact that features common in spoken and

\footnotetext{
${ }^{15}$ E.g. the subjunctive as present in "If I were a boy" (Beyoncé).
} 
informal registers are regularly ignored or underrepresented in learner grammars, FLE materials and textbooks (Cullen, 2012). ${ }^{16}$

A similar situation applies to the introduction of specific properties of scripted and performed texts (such as lyrics) as a hybrid category that unites characteristics of (typically) spoken and (typically) written production. Overall, using (non-standard) material from pop lyrics can be viewed as a chance to exploit a natural platform for the discussion of language topics and to introduce "syllabus-independent [...] grammar" (Dirven, 1990: 8); that is, grammatical variants (often informal or non-standard) that do not regularly form part of institutionalized language education but are highly instrumental in students' actual language use.

From a broader perspective, this can also be connected (i) to discussions of what counts as an appropriate target in FLE and (ii) to the contention that the majority of FL learners no longer strives for the ideal of near-native (and for English, British English) proficiency, but rather takes a utilitarian position. Proponents of this view recognize that "the lingua franca, in the first stage, has a communicative function, utilized to unite people from diverse cultures" (Modiano, 1999: 12). Eventually, this aspect links nicely with pop culture (and lyrics), insofar as "[i]n the second phase, the lingua franca is the bearer of new phenomena characteristic of global culture" (Modiano, 1999: 12; see also Section 4.2).

On a related note, the illustration of non-standard features of a language and register variation may also help us to move away from viewing (and teaching) foreign languages as something stable and fixed (Pennycook, 2010). Using relevant material may help to counter prescriptivist attitudes and practices as well as preconceived notions of languages (ideally) being static $^{17}$ and the standard variety as the "pure" form of a language. This has appropriately been summed up by Leech (1994: 20), who argues that "[t]he discovery that native speakers use the language in unforeseen ways and in ways which may even contradict the grammar 'experts' is itself a salutary experience, which teachers can hand to their own learners". It is also evident that such types of instruction more adequately map linguistic realities. Using authentic texts such as

\footnotetext{
${ }^{16} \mathrm{Cf}$. Azaryad Shechter (2018) for a similar line of reasoning using another pop culture artifact, TV series.

${ }^{17}$ Another issue not explicitly treated here is the fact that a considerable number of the non-standard forms can be motivated as historical remnants. Such issues may be of bigger interest for highly advanced learners or students of linguistics.
} 
pop lyrics arguably is conducive to the impact of such approaches, with the ultimate aim of a "reflexive stance towards linguistic conventions" (Stamou, 2012: 313). At the same time, closer linguistic analysis may serve to show that register variation (and this equally applies to other types of variation; see Section 4.2) is systematic and regular. ${ }^{18}$

\subsection{Grammaticality and variation}

It has been recognized for a long time that "linguistic differences appear in regional variations and dialects in songs from different countries" (Failoni, 1993: 102). Thus, in addition to register variation, using non-standard material as conveniently contained in pop lyrics may also provide a welcome way to introduce other types of variation beyond register variation, namely regional and social variation. The main point to be addressed here is to raise students' awareness of how "a language" can actually be defined, and to make them notice that in real life they will not only encounter the standard variety (or even rather a single standard variety) as represented in the bulk of FLE textbooks and materials, but rather a diverse range of actual usages. This is particularly relevant for students of pluricentric languages, such as English or Spanish, but can be considered valid for most, if not all, modern languages taught. Again, it is suggested that pop lyrics may serve as a good source of illustration.

The point to be made evident is that actual language use and the ensuing occurrence of nonstandard features (see Section 3.2) may to a certain degree be determined by the regional and social background of the artists, or, viewed more generically, of a speaker. Pop lyrics data can be employed to illustrate grammatical (and certainly other) differences between the major varieties American and British English (why does one artist use have got, the other only have or got?) and to introduce variants that are used in regional dialects. Relating back to the issue of register awareness (see Section 4.1), it could also be discussed why certain artists known to be dialect speakers (as could be illustrated by conversational data, e.g. from a recorded interview), do not or only selectively use these dialectal features in their singing (addressing the issues of styling,

\footnotetext{
${ }^{18}$ It is evident that the boundaries of a linguistic system may be stretched for creative purposes. See, e.g., López Rúa (2010) for an analysis of lexical creativity in the formation of band names or Trotta (2013) for an assessment of neologisms in lyrics. The seemingly unsystematic use of language as described in these lexical investigations is different from grammatical variation as it clearly operates above the level of conscience.
} 
marketability and (subcultural) identity; cf. Preisler, 1999; Trotta, 2013). In addition, pop lyrics could conveniently be used to introduce language contact varieties such as Jamaican Creole (featuring in reggae, for instance) and language use in sociolects such as African American English (AAE).

To take one case in point, with regard to AAE it may already have transpired from the examples presented in Section 3.2 that relevant non-standard uses are especially salient and frequent in the related genre of rap music (as shown in (42), simultaneously illustrating a nonstandard second person pronoun, copula deletion and the negator ain't). ${ }^{19}$

(42) Y'all $\varnothing$ a whole lot of things but you still ain't this (Drake: Grammys)

For rap, it has been argued that using features of AAE is a trademark characteristic to establish linguistic "realness" (Edwards \& Ash, 2004: 175; cf. Alim, 2006; Werner, 2019), that is, credibility among fellow artists and the audience as an authentic member of a social (and speech) community (crucially in defiance of standard linguistic and cultural norms; Morgan, 2001). Above all, a discussion of this "Black normativity" (Cutler, 2009: 80) may lead FL learners to reassessments of what counts as grammatical and acceptable (and thus carries prestige) in certain sociocultural domains (see also Trotta, 2013). In addition, this opens up an avenue for connecting the area of language use to issues of language policy (cf. the anti-establishment stance expressed in rap), of social realities (e.g. why does language use correlate with social class and ethnic affiliation?), and of cultural identity and appropriation (e.g. why do rappers worldwide use linguistic characteristics of or derived from rap/AAE?).

In other words, using different linguistic features can be analyzed as an indicator of broader cultural differences and could usefully be explored with the help of song lyrics with the eventual aim of increasing cultural awareness (Failoni, 1993). Such an embedded approach

\footnotetext{
${ }^{19}$ In rap lyrics, we also find non-standard uses such as contracted modals (modal auxiliary + have), as in Who coulda ['could have'] known he'd grow to be a poet and not know it (Eminem: Almost famous). Note, however, that this phenomenon is no longer restricted to use in this genre, as exemplified in the lyrics of the (white) British pop singer Ed Sheeran: And if your DVD breaks today you shoulda ['should have'] got a VCR (Ed Sheeran: Wake me up).
} 
simultaneously serves (i) to broaden the linguistic perspective to cultural content especially relevant for the FL learners (as it arguably is of concern for their native-language peers; see Duff \& Zappa-Hollman, 2013), (ii) to assess wider issues such as "global flows of language and culture" (Pennycook, 2010: 65), and (iii) to address longstanding calls (e.g. Little \& Singleton, 1991) for the integration of pragmatic, socio-linguistic and social information into grammar instruction, which also helps us to go beyond a view of "languages as objects in isolation" (Pennycook, 2010: 81).

\section{Conclusion}

With the present paper, I have shown that authentic pop culture material can be used in FLE well beyond conventional areas (such as listening comprehension or vocabulary, or even just as optional "fun" material), and that the occurrence of non-standard features (and their purported ungrammaticality) should be viewed as a fact supporting learning rather than as something to be ignored (or to leave for learners to explore for themselves). I connected this argument to pop lyrics and suggested that using this register is especially suitable for such purposes. Relating the findings of a qualitative corpus study of pop lyrics to the broader issue of how developing language awareness as an overall pedagogical goal in FLE can be achieved, I argued that dealing with such features (and contrasting them with standard usage) opens avenues (i) for structural work on a wide range of features and, more importantly, (ii) for work on issues such as register awareness as well as variation and complexity of pluricentric languages.

To further deal with the broader issue of language awareness, with more advanced students it is also conceivable to discuss structural (e.g. rhyme and meter) and sociolinguistic (e.g. representation of identity) motivations behind the occurrence of "contested grammar" (Trotta, 2013: 569); that is, contested if a stance strongly oriented toward standard (formal written) usage is taken. Other advanced issues are contrastive aspects and historical developments, turning the focus to the dynamic and ever-changing nature of languages. An example from the current data (see examples (1) to (5) above) would be the differentiation in the system of personal pronouns between a singular and plural variant of the second person. The latter ones may be of particular interest as there is no dedicated second person plural form in the 
standard system of personal pronouns of English (any longer) and as the native languages of the FL learners (or other foreign languages they know) may have different pronoun systems altogether (e.g. with a dual or with a honorific form). Again, this helps to question preconceived notions of "fixed" and "pure" forms of languages (Pennycook, 2010).

In any case, if pop lyrics and other suitable material are used in ways as described above importantly under the condition of emphasizing the systematicity of variation across social and regional boundaries - this may invariably lead students to embrace variation and diversity (cf. Reaser \& Adger, 2007), and eventually to acknowledge the multifaceted and pluricentric nature of languages. This can moreover be considered an emergent topic in FLE (see, e.g., Farrell \& Martin, 2009; Pennycook, 2017; Rose \& Galloway, 2019) and critically engaging with it therefore is of prime concern for all language educators.

Yet, this does not mean that using pop culture material and particularly pop lyrics represents a silver bullet in FLE in general, let alone to establish language awareness. It is evident that FL students have to be made familiar with a broad range of registers and linguistic realizations (both from pop culture and other sources) to develop language awareness and to become functional in a target language. However, there is strong evidence that using pop cultural material such as lyrics can serve as a convenient starting point and a highly valuable resource, with concrete implementations, which could not be covered in the present contribution, to be determined by language educators and materials designers.

\section{Acknowledgements}

I would like to thank Joe Trotta and two anonymous reviewers for their comments, which have helped to improve the manuscript. A selection of the above ideas was first presented as part of a plenary talk given at the $4^{\text {th }}$ Nordic Journal of Modern Language Methodology Conference: Foreign Language Education and Learning in the $21^{\text {st }}$ Century. I would like to thank the organizers, especially Eli-Marie Danbolt Drange and Lenka Garshol, for their invitation and hospitality, as well as the audience for their feedback. 


\section{References}

Abbott, M. (2002). Using music to promote L2 learning among adult learners. TESOL Journal, 11(1), 10-17. https://doi.org/10.1002/j.1949-3533.2002.tb00061.x

Alisaari, J., \& Heikkola, L. M. (2017). Songs and poems in the language classroom: Teachers' beliefs and practices. Teaching and Teacher Education, 63, 231-242. https://doi.org/10.1016/j.tate.2016.12.021

Alim, H. S. (2006). Roc the mic right: The language of hip hop culture. London: Routledge. Andrews, S. J. (2008). Teacher language awareness. In Cenoz, J., \& Hornberger, N. H. (Eds.), Encyclopedia of language and education. Volume 6: Knowledge about language (pp. 287298). Heidelberg: Springer.

Anthony, L. (2018). AntConc (3.5.6). Tokyo: Waseda University. https://www.laurenceanthony.net/software/antconc/

Arnold, J., \& Herrick, E. (2017). New ways in teaching with music. Alexandria: TESOL Press.

Azaryad Shechter, D. A. (2018). Overcoming the grammar barrier in foreign language learning: The role of television series. Journal of Language and Education, 4(2), 92-104. https://doi.org/10.17323/2411-7390-2018-4-2-92-104

Baron, A. (2017). VARD 2. Lancaster: UCREL. https://ucrel.lancs.ac.uk/vard/about/

Bell, A., \& Gibson, A. (2011). Staging language: An introduction to the sociolinguistics of performance. Journal of Sociolinguistics, 15(5), 555-572. https://doi.org/10.1111/j.14679841.2011.00517.x

Bértoli, P. (2018). Song lyrics: From multi-dimensional analysis to the foreign language classroom. In Werner, V. (Ed.), The language of pop culture (pp. 210-229). New York: Routledge. https://doi.org/10.4324/9781315168210

Billows, F. L. (1961). The techniques of language teaching. London: Longman.

Budden, J. (2008). Using music and songs. TeachingEnglish. https://www.teachingenglish.org.uk/article/using-music-songs

Carter, R., \& McCarthy, M. (2017). Spoken grammar: Where are we and where are we going? Applied Linguistics, 38(1), 1-20. https://doi.org/10.1093/applin/amu080

Coupland, N. (2011). Voice, place and genre in popular song performance. Journal of Sociolinguistics, 15(5), 573-602. https://doi.org/10.1111/j.1467-9841.2011.00514.x

Cullen, R. (2012). Grammar instruction. In Burns, A., \& Richards, J. C. (Eds.), Pedagogy and practice in second language teaching (pp. 258-266). Cambridge: Cambridge University Press.

Cullen, R., \& Kuo, I.-C. (2007). Spoken grammar and ELT course materials: A missing link? TESOL Quarterly, 41(2), 361-386. https://doi.org/10.1002/j.1545-7249.2007.tb00063.x

Cutler, C. (2009). "You shouldn't be rappin', you should be skateboardin' the X-Games": The coconstruction of whiteness in an MC battle. In Alim, H. S., Ibrahim, A., \& Pennycook, A. (Eds.), Global linguistic flows: Hip hop cultures, youth identities, and the politics of language (pp. 79-94). New York: Routledge. https://doi.org/10.4324/9780203892787

Dethier, B. (2003). From Dylan to Donne: Bridging English and music. Portsmouth: Heinemann. 
Dirven, R. (1990). Pedagogical grammar. Language Teaching, 23(1), 1-18. https://doi.org/10.1017/S0261444800005498

Dolean, D. D. (2016). The effects of teaching songs during foreign language classes on students' foreign language anxiety. Language Teaching Research, 20(5), 638-653. https://doi.org/10.1177/1362168815606151

Dörnyei, Z. (2001). Motivational strategies in the language classroom. Cambridge: Cambridge University Press.

Dubin, F. (1975). Rock, pop, and folk music: An overlooked resource. Englisch, 10(3), 109-113.

Duff, P. A., \& Zappa-Hollman, S. (2013). Using popular culture in language teaching. In Chapelle, C. (Ed.), The encyclopedia of applied linguistics (pp. 5997-6002). Malden: Wiley-Blackwell. https://doi.org/10.1002/9781405198431.wbeal1239

Edwards, W. F., \& Ash, L. (2004): AAVE features in the lyrics of Tupac Shakur: The notion of "realness". Word, 55(2), 165-178. https://doi.org/10.1080/00437956.2004.11432544

Engh, D. (2013). Effective use of music in language-learning: A needs analysis. Humanising Language Teaching, 15(5). https://www.hltmag.co.uk/oct13/mart03.htm.

Failoni, J. W. (1993). Music as means to enhance cultural awareness and literacy in the foreign language classroom. Mid-Atlantic Journal of Foreign Language Pedagogy, 5(1), 97-108.

Farrell, T. S. C., \& Martin, S. (2009). To teach Standard English or World Englishes? A balanced approach to instruction. English Teaching Forum, 47(2), 2-7.

Fernández Gavela, M. D. (2015). The grammar and lexis of conversational informal English in advanced textbooks. Newcastle: Cambridge Scholars.

Fetzer, Anita. (2004). Recontextualizing context: Grammaticality meets appropriateness. Amsterdam: Benjamins. https://doi.org/10.1075/pbns.121

Fonseca Mora, M., \& Gant, M. (2016). Melodies, rhythm and cognition in foreign language learning. Newcastle: Cambridge Scholars.

Gabe, G. (2015). Song lyrics hit the SERPs. Search Engine Land. https://www.searchengineland.com/song-lyrics-hit-serps-analyzing-google-bing-traffic-5large-scale-lyrics-websites-case-study-215848

Gosselin, P.-Y. L. (2017). The effects of language on English language learners' music preferences. International Journal of Music Education, 35(2), 216-226. https://doi.org/10.1177/0255761415582346

Gottfried, T. L. (2007). Music and language learning: Effect of musical training on learning L2 speech contrasts. In Bohn, O.-S., \& Munro, M. J. (Eds.), Language experience in second language speech learning (pp. 221-237). Amsterdam: Benjamins. https://doi.org/10.1075/1llt.17.21got

Gravenall, B. (1949). Music in language-teaching. English Language Teaching, 3(5), 123-127.

Green, L. (2007). Syntactic variation. In Bayley, R., \& Lucas, C. (Eds.), Sociolinguistic variation: Theories, methods, and applications (pp. 24-44). Cambridge: Cambridge University Press.

Groot, A. de, \& Smedinga, H. (2014). Let the music play! A short-term but no long-term detrimental effect of vocal background music with familiar language lyrics on foreign language vocabulary learning. Studies in Second Language Acquisition, 36, 681-707. https://doi.org/10.1017/S0272263114000059 
Hagedorn, L. (2019). Informality and recent language change in pop versus rock lyrics. MA thesis, University of Bamberg.

Hancock, M. (2006). Singing grammar. Cambridge: Cambridge University Press.

Huber, M. (2010). Songs in Austrian course books for English as a Foreign Language. MA thesis, University of Vienna. https://othes.univie.ac.at/12273/1/2010-11-27_0506013.pdf

Jantzen, M. G., Large, E. W., \& Magne, C. (2016). Overlap of neural systems for processing language and music. Frontiers in Psychology, 7(876), 1-2. https://doi.org/10.3389/fpsyg.2016.00876

Keskinen, O. (2014). Use of music in English classrooms in lower and upper secondary schools and at university of applied sciences: A comparative study on teachers' perceptions and practices. Graduate thesis, University of Jyväskylä. https://jyx.jyu.fi/handle/123456789/44195

Kortmann, B., \& Lunkenheimer, K. (2013). The electronic world atlas of varieties of English. Leipzig: Max Planck Institute for Evolutionary Anthropology. https://www.ewave-atlas.org

Leech, G. (1994). Students' grammar - teachers' grammar - learners' grammar. In Bygate, M., Tonkyn, A., \& Williams, E. (Eds.), Grammar and the language teacher (pp. 17-30). New York: Prentice Hall.

Lems, K. (2005). Music works: Music for adult English language learners. New Directions for Adult and Continuing Education, 107, 13-21. https://doi.org/10.1002/ace.185

Li, X., \& Brand, M. (2009). Effectiveness of music on vocabulary acquisition, language usage, and meaning for mainland Chinese ESL learners. Contributions to Music Education, 36(1), 73-84.

Little, D., \& Singleton, D. (1991). Authentic texts, pedagogical grammar and language awareness. In James, C., \& Garrett, P. (Eds.) Language awareness in the classroom (pp. 123-132). London: Longman.

Loewen, S. (2015). Introduction to instructed second language acquisition. London: Routledge. https://doi.org/10.4324/9780203117811

López Rúa, P. (2010). Making and breaking the rules: Lexical creativity in the alternative music scene. Language Awareness, 19(1), 51-67. https://doi.org/10.1080/09658410903197363

Lorenzutti, N. (2014). Beyond the gap fill: Dynamic activities for song in the EFL classroom. English Teaching Forum, 52(1), 14-21.

Marone, V. (2018). Teaching English through music videos. In Liontas, J. I. (Ed.), The TESOL encyclopedia of English language teaching. Malden: Wiley-Blackwell. https://onlinelibrary.wiley.com/doi/10.1002/9781118784235.eelt0849

Mobbs, A., \& Cuyul, M. (2018). Listen to the music: Using songs in listening and speaking classes. English Teaching Forum, 56(1), 22-29.

Modiano, M. (1999). Standard English(es) and educational practices for the world's lingua franca. English Today, 15(4), 3-13. https://doi.org/10.1017/S0266078400011196

Morgan, M. (2001). "Nuthin' but a G thang": Grammar and language ideology in hip hop identity. In Lanehart, S. L. (Ed.), Sociocultural and historical contexts of African American English (pp. 187-209). Amsterdam: Benjamins. https://doi.org/10.1075/veaw.g27.13mor

Motschenbacher, H. (2016). A corpus linguistic study of the situatedness of English pop song lyrics. Corpora, 11(1), 1-28. https://doi.org/10.3366/cor.2016.0083 
Murphey, T. (1990). Song and music in language learning: An analysis of pop song lyrics and the use of song and music in teaching English to speakers of other languages. Frankfurt: Lang.

Nielsen. (2017). Time with tunes: How technology is driving music consumption. https://www.nielsen.com/us/en/insights/news/2017/time-with-tunes-how-technology-isdriving-music-consumption.html

North, A. C., Hargreaves, D. J., \& O’Neill, S. A. (2000). The importance of music to adolescents. The British Journal of Educational Psychology, 70(2), 255-272. https://doi.org/10.1348/000709900158083

Patel, A. D. (2017). Using music to study the evolution of cognitive mechanisms relevant to language. Psychonomic Bulletin and Review, 24(1), 177-180. https://doi.org/10.3758/s13423-016-1088-4

Pavia, N., Webb, S., \& Faez, F. (2019). Incidental vocabulary learning through listening to songs. Studies in Second Language Acquisition, 41(4), 745-768. https://doi.org/10.1017/S0272263119000020

Pennycook, A. (2010). Nationalism, identity and popular culture. In Hornberger, N. H., \& McKay, S. L. (Eds.), Sociolinguistics and language education (pp. 62-86). Bristol: Multilingual Matters.

Pennycook, A. (2017). The cultural politics of English as an international language. London: Routledge. https://doi.org/10.4324/9781315225593

Preisler, B. (1999). Functions and forms of English in a European EFL country. In Bex, T., \& Watts, R. (Eds.), Standard English: The widening debate (pp. 239-267). London: Routledge.

Reaser, J., \& Adger, C. (2007). Developing language awareness materials for nonlinguists: Project lessons learned from the Do You Speak American? curriculum development. Language and Linguistics Compass, 1(3), 155-167. https://doi.org/10.1111/j.1749818X.2007.00011.X

Richards, J. (1969). Songs in language learning. TESOL Quarterly, 3(2), 161-174.

Rose, H., \& Galloway, N. (2019). Global Englishes for language teaching. Cambridge: Cambridge University Press. https://doi.org/10.1017/9781316678343

Saricoban, A., \& Metin, E. (2000). Songs, verse and games for teaching grammar. The Internet TESL Journal, 6. https://www.iteslj.org/Techniques/Saricoban-Songs.html

Schön, D., Gordon, R. L., \& Besson, M. (2005). Musical and linguistic processing in song perception. Annals of the New York Academy of Sciences, 1061, 71-81. https://doi.org/10.1196/annals.1360.006

Scott Langeland, A. (2013). Action research into the use of popular music: A goldmine worth exploring in the ELT secondary-school classroom? Nordic Journal of Modern Language Methodology, 2(1). https://journal.uia.no/index.php/NJMLM/article/view/88

Smith, G. P. (2003). Music and mondegreens: Extracting meaning from noise. ELT Journal, 57(2), 113-121. https://doi.org/10.1093/elt/57.2.113

Sposet, B. A. (2008). The role of music in second language acquisition: A bibliographical review of seventy years of research, 1937-2007. Lewiston: Edwin Mellen Press. 
Stamou, A. G. (2012). Representations of linguistic variation in children's books: Register stylisation as a resource for (critical) language awareness. Language Awareness, 21(4), 313-329. https://doi.org/10.1080/09658416.2011.604421

Staub, P., \& Zentz, J. (2017). Fixin' to. Yale Grammatical Diversity Project: English in North America. https://ygdp.yale.edu/phenomena/fixin-to

Stocker, C. (1923). Teaching French through folk songs. The Modern Language Journal, 7(5), 285-288. https://doi.org/10.2307/313835.

Summer, T. (2011). An evaluation of methodological options for grammar instruction in EFL textbooks: Are methods dead? Heidelberg: Winter.

Summer, T. (2018). An analysis of pop songs for teaching English as a foreign language: Bridging the gap between corpus analysis and teaching practice. In Werner, V. (Ed.), The language of pop culture (pp. 187-209). New York: Routledge. https://doi.org/10.4324/9781315168210

Svalberg, A. M.-L. (2012). Language awareness in language learning and teaching: A research agenda. Language Teaching, 45(3), 376-388. https://doi.org/10.1017/S0261444812000079

Syed, Z. (2001). Notions of self in foreign language learning: A qualitative analysis. In Dörnyei, Z., \& Schmidt, R. W. (Eds.), Motivation and second language acquisition (pp. 127-148). Honolulu: University of Hawai' 'i at Mānoa.

Tegge, F. (2015). Investigating song-based language teaching and its effect on lexical learning. $\mathrm{PhD}$ dissertation, Victoria University Wellington.

Tegge, F. (2018). Pop songs in the classroom: Time-filler or teaching tool? ELT Journal, 72(3), 274-284. https://doi.org/10.1093/elt/ccx071

Thaler, E. (2012). 10 modern approaches to teaching grammar. Paderborn: Schöningh.

Thaler, E. (2018). Singer-songwriters: Music and poetry in language teaching. Tübingen: Narr.

Tomlinson, B. (2017). Achieving a match between SLA theory and materials development. In Tomlinson, B. (Ed.), SLA research and materials development for language learning (pp. 1-22). New York: Routledge.

Trotta, J. (2010). Whose rules rule? Grammar controversies, popular culture and the fear of English from below. Nordic Journal of English Studies, 9(3), 41-65. http://ojs.ub.gu.se/ojs/index.php/njes/article/view/449/429

Trotta, J. (2013). What Meatloaf won't do for love: A catalog of mystery, imagination and linguistic rebellion in popular music. In Bergh, G., Bowen, R., \& Mobärg, M. (Eds.), Language, football, and all that jazz (pp. 543-573). Göteborg: Acta Universitatis Gothenburgensis.

Turpin, M., \& Stebbins, T. (2010). The language of song: Some recent approaches in description and analysis. Australian Journal of Linguistics, 30(1), 1-17. https://doi.org/10.1080/07268600903133998

Werner, R. (2018). Music, movement and memory: Pedagogical songs as mnemonic aids. TESOL Journal, 9(4), 1-11. https://doi.org/10.1002/tesj.387

Werner, V. (2012). Love is all around: A corpus-based study of pop music lyrics. Corpora, 7(1), 19-50. https://doi.org/10.3366/cor.2012.0016

Werner, V. (2018). Linguistics and pop culture: Setting the scene(s). In Werner, V. (Ed.), The language of pop culture (pp. 3-26). New York: Routledge. https://doi.org/10.4324/9781315168210 
Werner, V. (2019). Assessing hip-hop discourse: Linguistic realness and styling. Text \& Talk, 39(5), 671-698. https://doi.org/10.1515/text-2019-2044

Werner, V. (Forthcoming). Teaching grammar through pop culture. In Werner, V., \& Tegge, F. (Eds.). Pop culture and language education: Theories and practices. New York: Routledge.

Werner, V. (submitted a). A review of classroom-based intervention studies applying lyrics-based language teaching (1972-2019).

Werner, V. (submitted b). Catchy and conversational? A register analysis of pop lyrics.

Werner, V., \& Tegge, F. (Forthcoming). Learning languages through pop culture/learning about pop culture through language. In Werner, V., \& Tegge, F. (Eds.). Pop culture and language education: Theories and practices. New York: Routledge.

Williamson, J., \& Reeve, C. (1987). Look what they've done to my song. Modern English Teacher, 14(4), 33-36.

Zhou, Z. (2016). A music-based agenda for teaching English as a second/foreign language: Common themes and directions. In Fonseca Mora, M., \& Gant, M. (Eds.), Melodies, rhythm and cognition in foreign language learning (pp. 163-173). Newcastle: Cambridge Scholars.

Ziegler, N. (2016). Enhancing the use of music in language learning through technology. In Moeller, A. J. (Ed.), Fostering connections, empowering communities, celebrating the world: 2016 report of the Central States Conference on the Teaching of Foreign Languages (pp. 59-78). Richmond: Terry. 